\title{
Back to School-Resilience among Student Mothers in Ghana: The case of Nkawkaw.
}

\author{
Zariatu Ibrahim \\ Student, Masters in Sociology \\ Sakarya University, Turkey. \\ DOI: 10.31364/SCIRJ/v6.i11.2018.P1118585 \\ http://dx.doi.org/10.31364/SCIRJ/v6.i11.2018.P1118585
}

\begin{abstract}
While the negative consequences of teenage pregnancy are well documented and widely discussed in the literature (Bonell, 2004, Harding, 2003, Oyedele et al. 2015) far less attention has been paid to girls who have successfully overcome the challenges associated with teen birth by going back to school after giving birth. This paper explores the protective factors that serve as a shock absorber of the risk factors which influence the resilience building process of young mothers in their decision to return to school after giving birth. Using the qualitative method of enquiry, purposive and snowball sampling techniques were adopted and an in-depth interview of 10 respondents were conducted and analyzed. The results show that student mothers' main source of social and financial support is from their parents, the reason that influenced their resilience decision making is because they have higher aspirations. Factors such as financial difficulty, stigmatization, and lack of social support among others hindered the resilience building process. The conclusion is that for young mothers to develop resilience towards education, they need to receive financial and social support from significant others.
\end{abstract}

Index Terms - Resilience, Student Mothers, Teen birth, Ghana, Nkawkaw

\section{INTRODUCTION}

There has been a significant increase in the number of school dropouts in Ghana. The Global Initiative on out-of-school children, 2012 indicated that roughly $4 \%$ of children were dropouts in 2008 after having enrolled in the primary school while less than $1 \%$ of children were dropouts in 2003. Imoro, 2009 studied the dimensions of school dropout in the Asutifi district and found out that the rates in the Junior High School is higher than that of the primary schools and females were likely to dropout than males. The researcher indicated that one key reason for the higher dropout rates among girls was teenage pregnancy.

The Eastern region according to the Ghana Demographic and Health Survey, 2008 experienced a dropout rate of 3\%. The Chronicle News Paper on May $18^{\text {th }} 2015$ reported that 7,256 girls representing 33.69\% from six districts in the Eastern region of Ghana dropped out of basic school between the 2010/2012 academic year. According to statistics available, of the 21,537 girls who enrolled in the Junior High School One in 2010, only 14,281 sat for the Basic Education Certificate Examination in 2012 with the remaining 7,256 becoming dropouts in the six districts.

The 2014 regional report from the Ghana Health Service also showed that teenage pregnancy was a major factor of school dropout indicating that 13,520 girls between the ages of $13-15$ were pregnant across the region. Ghana web on $30^{\text {th }}$ July 2015 on their regional news mentioned that the absence of social amenities have triggered high rate of teenage pregnancy in Wurampong a farming community in the Yilo krobo district of the Eastern region of Ghana. Most of the girls in the community between the ages of $12-18$ have given birth(s), are pregnant or carrying babies without husbands. The situation has led to high rate of school dropouts in the area because teenage mothers feel reluctant to return to school after giving birth.

Despite the above mentioned statistics of school dropout as a result of teenage pregnancy, some teenagers are able to go back to school after giving birth. I am interested in knowing how these girls are able to overcome all the setbacks of teen birth and go back to school. I focused my study on the factors that helped these girls in their resilience process.

There have been a number of studies on resilience in the western world. Some of these studies were done on child development. Luthar et al. (2000) studied how some children are able to become successful despite the challenges they faced during childhood. Benard (1991) studied how protective factors from the family, school and community can help kids to develop resilience. Smith \& Carlson (1997) also studied how some youth are more resilient and overcome adversities. In Ghana, a few studies have been done on resilience. Antwi Bosiakoh (2013) studied resilience of adolescents to sex and teenage pregnancy and found out that of the 120 respondents, $40 \%$ of them had ever been pregnant and they used contraceptives to protect themselves from further pregnancy.

Adu-Gyamfi (2014), also studied the resilience of adolescents to sex and teenage pregnancy and found out that family especially mothers were the major source of capital, social and emotional support for ever pregnant girls. The researcher concluded that if ever pregnant girls get support from significant others they will be able to get their lives back by returning to school. 
Dawson \& Hosies, (2005) studied the education of pregnant young women and young mothers in England. The study covered 186 young mothers and young women of statutory school going age. The findings were that majority of the respondents stopped their education before pregnancy and those who tried to further after the pregnancy were truant because of the bullying from their peers and teachers. However, majority of the women reported that they will be more willing and punctual to further their education if they are offered appropriate non-judgmental support. Also, a lack of affordable and accessible child care was seen as a barrier to the education of young mothers and young women. The research concluded that, issues such as peer relationship, teaching styles, school location and family background affect young women's engagement with and perception of education, before, during and after pregnancy.

In both Western and non-Western countries, there is little emphasis on resilience in terms of reengagement of teenage mothers in school after delivery. This study seeks to fill that gap in the literature by exploring how teenage mothers develop resilience and go back to school after giving birth.

A plethora of studies have been done on teenage mothers (Antwi Bosiakoh, 2013; Adu- Gyamfi, 2014; Akpor, 2015; Bonel, 2004; Graham, 1991; Harding, 2003) most of which focus on the risk for mothers and children. Among others the risks include health risks; lower level of education; reduced employment opportunities; longer-term welfare dependency and the transfer of the disadvantages to their future generation. However, not all teenage mothers experience these poor and negative outcomes. Some are protected from risk or can overcome disadvantages (Collins, 2010). People who display resilient strategies become stronger by learning new skills, developing creative ways of coping, and the ability to overcome life's challenges (Luther \& Zelazo, 2003). According to Ruther (1990), the presence of numerous protective factors can increase a person's chance of overcoming adversities because these factors have the likelihood of reducing the effects of risks.

Despite teenage pregnancy being the highest cause of school dropout in Ghana, some teen mothers are able to overcome the challenges associated with it and go back to school. The theoretical basis that underlies this is the concept of resilience. Masten (2011) defined resilience by extending it to include how the individual adapts during or after experiencing the risk. In this paper I adopted the Masten's definition of resilience as "the study of the processes of the capacity for, or pathways and patterns of positive adaptation during or following significant threats or disturbances” (Masten, 2011:494).

The need to focus on strengths rather than our shortfalls is a new area of research. The ability to build upon strength rather than focusing on risk factors is seen as a good approach to promote the development of a child (Bernard, 1993). Building on strengths challenges an individual to go to higher levels with a sense of confidence that focusing on deficiencies does not provide (Wolin \& Wolin, 1993). Literature has shown that teenage mothers get social and economic support from family, school, community and peers. These supports help them to get their lives back by returning to school.

\section{COMING TO UNDERSTAND THE LIVES OF STUDENT MOTHERS}

This paper is derived from my undergraduate dissertation which was focused on knowing the factors that influence the resilience building process of student mothers in Nkawkaw. Using the snowball technique I conducted 10 in-depth, open ended and tape-recorded interviews with young girls between the ages of 13-19 who have given birth and are furthering their education. I held interviews in the local dialect Twi and English. I fully transcribed and translated these interviews into English. One respondent was pregnant at age 13 and another at 14, three at age 16, two at age 17, one at age 18 and two at age 19 . I have to mention that most of these girls were in the Junior High School one when they got pregnant. At the time of the study 5 of them had completed their studies completely, 4 still in the JHS and 1 in Senior High School. When respondents were asked what happened to them after they gave birth, it was interesting to know that half the number of respondents left their babies home when they were only four months old and returned to school. Some of the respondent were running back home during break time to breastfeed their babies while others were only feeding them with food because the breast milk was not enough.

Also, I tried to find the link between the time of dis-engagement from school and the time of pregnancy. According to a study done by Hosie \& Dawson (2005), on the education of pregnant young women and young mothers in England, they discovered that many pregnant young women and young mothers' disengagement from education occurred prior to pregnancy with only a few young women attending school regularly at the point of conception. In contrast, this research found out that pregnant young women disengagement occurred after many months into their pregnancy. It was interesting when young mothers reported that even after realizing that they were pregnant they continued going to school. Apart from $30 \%$ of respondents who said they stopped going to school when they realized they were pregnant, the remaining $70 \%$ said they were aware but decided to go to school because they were strong and did not experience any morning sickness. Moreover, their pregnancy was not visible so they did not know why they should stop attending school. It was interesting when the researcher observed that the minimum months at which young mothers attended school with pregnancy was two months while the maximum was six and a half months. In the words of May, (one respondent)

Yes, for six and a half months, my mother didn't know I was pregnant, it was my friend who finally leaked it to my mum because she was afraid I will give birth in school. It was the same period that we were having our inter-schools sports competition and I even played football with it. When finally my mother got to know she hid my school uniform just to prevent me from going to school. She told me I have to stay home so that she will prepare 'abemuduro' (a local soup mostly prepared for pregnant women) for me. And also if I continue going to 
school someone who has 'bad eyes' can use 'asram' (a disease that mostly affect children caused by bad people) to harm the child.

\section{FACTORS THAT INFLUENCE THE RESILIENCE BUILDING PROCESS OF STUDENTS MOTHERS}

The decision of going back to school after having a baby by young mothers is a difficult one which can only be made by strong determined young mothers who have some set of goals to achieve in life. When young mothers were asked about what made them to take the decision of going back to school they gave reasons such as having higher aspirations like becoming nurses, climbing higher the educational ladder, having a dream, the been to label and the advice from family.

Respondents desire to achieve their dreams in life influenced their decision to return to the classroom after giving birth. Young mothers have the dream of becoming nurses, bank managers, policewomen and teachers. All these according to them can come to pass if they go to school. Similarly, in Antwi-Bosiakoh (2013) she found out that in the resilience building process, education and future aspiration were the important factors that influence the process. Aronowitz, (2006) also asked adolescents what helped them to bounce back after facing challenges and the response was that, they had vision for the future as well as having the feeling that they will actually succeed which kept them moving.

The been to label which makes respondents see themselves as part of those who have been to school also served as a steering wheel. Some respondents said that they were in school because they cannot stand their mates going to school while they are home. They expressed the feeling of shyness whenever they saw their mates. This made them think of going back to school. In some cases respondents were of the view that, they were going to school because they wanted to let the fathers of their babies see them and bow down in shame. Two respondents opined that going back to school as young mothers served as a source of prestige to them. They are always used as a point of reference to other young mothers who are home and feel reluctant to go back to school.

However, it is important to add here that, in as much as young mothers have higher aspirations and dreams to further their education, there are setbacks that prevent them from achieving this dream. Young mothers expressed their interest in climbing the educational ladder but were quick to add that they could do so if only they got support from significant others. Some respondents said they had no hope of getting help and so that was the end for them. This is how some expressed their worries:

I want to become a policewoman. I would like to go to a tertiary institution but as it stands now I don't have any hope. I don't know where the help will come from... Maa Akos

Well...for my dream...I wanted to be a nurse but unfortunately there is no help so for now I want to learn sewing. Franca

When I complete and I get help from my parents I want to become a nurse but when I don't get then that is the end. Asibi

This points to the fact that resilience building is not just a function of one party but a collaborative process by which young mothers and significant others have to play their roles. If the young mothers are willing to return to school, then there should be someone to help them both socially and financially to be able to build their resilience.

In the process of building resilience among young mothers, one thing that cannot be overlooked is the source of advice. Young mothers need people who will be motivating them and letting them understand that all hope is not lost and that they can make it even after having a baby. About $60 \%$ of young mothers said that their mothers played a significant role in their reengagement. According to young mothers, it was their mothers who advised them to return to school. Some respondents told the researcher that they had already given up on education but their mothers were able to convince them to go back. This supports the findings of Antwi- Bosiakoh, (2013) which says that mother's advice for teen mothers was a major factor in the resilience building process of adolescents against teenage pregnancy. Similarly, LaFromboise et al., (2006) also found out that warm and supportive mothers were a source of prosocial behavior. Some respondents had this to say:

Ooh they were even forcing me to come ... it got to a time I decided not to come back to school because my mates I completed with were all working, so my mum advised me that I should return to school because education is not a waste. Ama.

I will say mummy... when I was pregnant I didn't have the chance to smile...I was always sad, so she was always like don't worry you will go back to school. Franca.

Despite, the aforementioned factors that help young mothers in their resilience process there are also negative factors that hinder the process as well. The problem of stigmatization was one factor stressed by young mothers. They did not like the fact that they were being called "bornone" by their peers.

Another issue that came up as a hindrance was the issue of money. Young mothers were depending on their parents for the financial support of themselves as well as their babies. This became a challenge since their monies had to be divided into two 
for their babies and themselves. In some instances young mothers had to help their parents by engaging in petty trading. According to some respondents,

My challenge...hmm..it was hard...like let's say me going back to school and my little boy also. Like I said if I was supposed to take GHC4, Michael (her baby) will have to take two cedis and the remaining two cedis too will come to me... my dear it wasn't easy. Franca

Okay... I don't come to school regularly, and also my school fees. Because my child is schooling if the school asks for something I have to use my school fees to pay for him. So sometimes I am sacked. Precious

The challenge was that my father told me he didn't have money to support me so I should go and marry and stop the school. I had to sell water melon and meat pie to make money. So after I entered school he is now helping me. Asibi

It was observed also that in the re-engagement process of young mothers, the issue of who takes care of the baby when young mothers go to school was a problem. In a situation where there is nobody at home, young mothers have to absent themselves to take care of the baby. This in the long run affects their performance in school. The researcher observed one respondent who had nobody to take care of her baby and so had to miss several mock exams.

Another challenge student mothers faced was that they could not get the time to learn because of their babies. This affected their performance. They emphasized that their performance had decreased as compared to when they did not have babies. In the words of some respondents,

I will say it has decreased because eerm... if I say I am going to study in the night, because I was not in the house during the day I have to go and wash and if the baby is crying I will not sleep, I am supposed to wake up and check what is wrong with her. And sometimes when I am in school I can be called that the baby is sick so I should come and take her to the hospital. Precious

Well...me for myself I could see that when I didn't have a baby my performance was good but when I came back after giving birth it decreased because the baby was just four months and I was always thinking about him when I was in school. So sometimes I run home to take care of him. Franca

\section{CONCLUSION}

Resilience is identified as a character trait that helps in resolving challenges in people's lives. Adolescents face an everchanging world and having enhanced resilience capabilities may serve them well. In order to empower young mothers to return to school there is first of all the need to create awareness of the importance of education in their lives and to let them know that getting pregnant does not mean the end to education. The school environment must be made conducive to accommodate young mothers who are willing to return to school. This can be achieved by headmasters/headmistresses making rules that will deter students from teasing young mothers who have returned to school. Further, young mothers need social and economic support from significant others such as the government, parents, peers and the community to enable them have a smooth journey in their educational life. When all these conditions are observed, the number of young mothers in school will increase and they can achieve their dreams.

Based on the findings of the study, recommendations are being made for Women Empowerment Agencies as well as Education policy makers in Ghana. The first recommendation is that there should be Community Based Agencies in place to counsel and guide young mothers on the importance of education and the need to pursue higher education. This will go a long way to motivate those who feel reluctant to return to school after giving birth. There should be separate or special educational institutions for young mothers since some of them feel shy to join the never pregnant girls in the same school and also to avoid being teased at school. Also, Policy makers should make the effort to provide affordable day-care institutions for young mothers to send their babies to when they are ready to start school. Finally, due to the financial challenges faced by young mothers in school, it is recommended that the government should help young mothers who are in school or who are willing to return to school with their school fees, feeding, clothing and learning materials. Finally, based on the limitation of the study to use a bigger sample size, it is recommended that, further studies should employ the quantitative method of enquiry to find out if the issues raised above can be generalized across Ghana.

\section{REFERENCES}

[1] Adu-Gyamfi, S. E. (2014, December). Social Resilience of Adolescent Girls' to Sex, Teenage pregnancy and Motherhood in Ghana. Dissertation Submitted to The Depatment of Sociology, University of Ghana in Partial Fulfilment of the Requirement for the Degree of Philosophy. Accra.

[2] Akpor, O. (2015). Community Participation in teenage pregnancy prevention programmes: A 
systematic review. Journal of Research in Nursing and Midwifery, 4(2), 24-36.

[3] Antwi-Bosiako, P. (2013). Navigating Around Teenage Pregnamcy: Resilience of Adolescent girls in Accra. Dissertation. Accra: University of Ghana.

[4] Aronowitz, T. (2006). The Role of "Envisoning the Future" In The Develpment of Resilience among At- Risk Youth. Public Health Nursing, 22(3), 200-208.

[5] Awusabo- Asare, K., Kumi- Kyereme, A. \& Biddlecom, A. (2007). Adolescents' Sexual and Reproductive Health: Qualitative Evidence from Ghana, Occasional Report. New York:

Guttmacher Institute.

[6] Barbara, C. (2010). Resilience in Teenage Mothers: A Follow Up Study.

[7] Benard, B. (1991, August). Fostering Resiliency in Kids: Protective Factors in the Family, school, and Community.

[8] Bonell, C. (2004). Why is teenage pregnancy conceptualized as a social problem? A review of quantitative research from the USA and UK. Culture, health \& sexuality, 6(3), 255-272.

[9] Chand, S. (2016, March 30). Employee Discipline: Meaning, Features and Objectives. Retrieved from www.yourarticlelibrary.com: http://www.slideshare.net/GeenoGeorge/employeediscipline-14653816

[10] Dawson, N., \& Hosie, A. (2005). The Education of Pregnant Young and Young Mothers in England. Bristol: University of Bristol.

[11] DFES. (2001). Guidance on The Education of School Age Parents. Retrieved from http://www.dfes.gov.uk/schoolageparents/

[12] Donaghey, M. V. (2013). Resilience among middle Students. Dissertion prepared for the degree of Doctor of Philosophy. University of North Texas.

[13] Employee Discipline. (2016, March 30). Retrieved from www.slideshare.net: http://www.slideshare.net/GeenoGeorge/employee-discipline-14653816

[14] Harding, D. J. (2003). Counter factual Models of Neighborhood Effects: The Effects of Neighborhood Poverty on dropping out and teenage Pregnancy. American Journal of Sociology, 109(3), 676-719.

[15] Hosie, A. (2003). Re-engagement and Re-integration of Pregnant Young Women and Young Mothers of School Age. University of Newcastle.

[16] Indutrial Relation Management. (2016, March 30). Retrieved from www.wisdomjob.com: http://www.wisdomjobs.com/e-university/industrial-relations-management-tutorial-357/employee-discipline-1901/types-ofdiscipline-11769.html

[17] LaFrombiose, T. D., Hoyt, D. R., Oliver, L., \& Whitebeck, L. B. (2006). Family, Community, and School Influences on Resilience among American Indian Adolescents in the Upper Midwest. Journal of Community Psychology, 34(2), 19-209.

[18] Luthar, S. S., \& Zelazo, L. B. (2003). Research on Resilience: An Integration Review. In S. Luthar, Resilience and Vulnerability: Adaptation in the Context of Childhood Adversities (pp. 510 - 549). Cambridge, UK: Cambridge Press.

[19] Luthar, S. S., Cicchetti, D., \& Becker, B. (2000). Research on Resilience: Response to Commentaries. Child Development, 71, 573-575.

[20] Masten, A. S. (2011). Resilence in Children threatened by Extreme Adversity: Frameworks for Research Practice and Translation Synergy. Development and Psychology, 23, 493-506.

doi:10.1017/509545794//000198

[21] Nicholas, F., \& Jessica, R. (2007, October). Reframing School Dropout as a Public Health Issue. Preventing Chronic Disease: Public Health Research, Practice and Policy, 4(4). 
[22] Obrist, O., Pfeiffer, C. \& Henry, R. (2010). Multi-Layered social Resilience: A New Approach in Mitigation Research. Progress in Development Studies, 10(4), 283-293.

[23] Oyedele, O., Wright, S., \& Maja, T. (2015). Community Participation In Teenage Pregnancy Prevention Programmes: A Systematic Review.International journal of Nursing Didactics, 5(05), 26-38. (1999). Teenage Pregnancy. Social Exclusion Unit. London: Stationery Office.

[24] Wang, M. C., \& Gordon, E. W. (1994). Educational Resilience in Inner-City America. Challenges and Prospects.

[25] Wolin, S. J., \& Wolin, S. (1993). The Resilience Self: How Survivors of Troubled Families Rise Above Adversity. NY: Villard Books.

[26] Zimmerman, M. A., Ramirez-Valle, J., \& Maton, K. I. (1999). Resilience among Urban African American Male Adolescent: A study of the protective effects of socio-political control on their mental health. American Journal of Community Psychology, 27. 